\title{
๖The Impact of Height-Independent Errors in State Variables on the Determination of the Daytime Atmospheric Boundary Layer Depth Using the Bulk Richardson Approach
}

\author{
TEMPLE R. LeE ${ }^{\mathrm{a}, \mathrm{b}}$ AND SANDIP PAL ${ }^{\mathrm{c}}$ \\ ${ }^{a}$ Cooperative Institute for Mesoscale Meteorological Studies, Norman, Oklahoma \\ ${ }^{\mathrm{b}}$ NOAA/ARL/Atmospheric Turbulence and Diffusion Division, Oak Ridge, Tennessee \\ ${ }^{\mathrm{c}}$ Atmospheric Science Group, Department of Geosciences, Texas Tech University, Lubbock, Texas
}

(Manuscript received 18 August 2020, in final form 14 October 2020)

\begin{abstract}
Rawinsonde observations have long been used to estimate the atmospheric boundary layer depth (BLD), which is an important parameter for monitoring air quality, dispersion studies, weather forecast models, and inversion systems for estimating regional surface-atmosphere fluxes of tracers. Although many approaches exist for deriving the BLDs from rawinsonde observations, the bulk Richardson approach has been found to be most appropriate. However, the impact of errors in the measured thermodynamic and kinematic fields on the estimated BLDs remains unexplored. We argue that quantifying BLD error ( $\delta \mathrm{BLD}$ ) estimates is equally as important as the BLDs themselves. Here we quantified $\delta$ BLD by applying the bulk Richardson method to 35 years of rawinsonde data obtained from three stations in the United States: Sterling, Virginia; Amarillo, Texas; and Salt Lake City, Utah. Results revealed similar features in terms of their respective errors. $\mathrm{A}-2^{\circ} \mathrm{C}$ bias in temperature yielded a mean $\delta$ BLD ranging from -15 to $200 \mathrm{~m}$. A $+2{ }^{\circ} \mathrm{C}$ bias in temperature yielded a mean $\delta$ BLD ranging from -214 to $+18 \mathrm{~m}$. For a $-5 \%$ relative humidity bias, the mean $\delta \mathrm{BLD}$ ranged from -302 to $+7 \mathrm{~m}$. For a $+5 \%$ relative humidity bias, the mean $\delta \mathrm{BLD}$ ranged from +2 to $+249 \mathrm{~m}$. Differences of $\pm 2 \mathrm{~m} \mathrm{~s}^{-1}$ in the winds yielded BLD errors of $\sim \pm 300 \mathrm{~m}$. The $\delta$ BLD increased as a function of BLD when introducing errors to the thermodynamic fields and decreased as a function of BLD when introducing errors to the kinematic fields. These findings expand upon previous work evaluating rawinsonde-derived $\delta \mathrm{BLD}$ by quantifying $\delta \mathrm{BLD}$ arising from rawinsonde-derived thermodynamic and kinematic measurements. Knowledge of $\delta \mathrm{BLD}$ is critical in, for example, intercomparison studies where rawinsonde-derived BLDs are used as references.
\end{abstract}

KEYWORDS: Boundary layer; Radiosonde observations; Error analysis

\section{Introduction}

The depth of Earth's atmospheric boundary layer (ABL) is a critical component for many applications including, e.g., weather and climate models, air quality and dispersion studies, and inversion systems used to estimate regional surface-atmosphere fluxes of tracers. Because the ABL depth (henceforth the BLD) governs the vertical mixing of passive tracers and aerosols, the afternoon BLD is an important variable for many applications. The afternoon BLD represents the maximum height to which surface-based pollutants disperse and thus is essential for studies of, e.g., dispersion of trace gases (e.g., Lee et al. 2018).

Many different platforms are used to determine ABL heights including masts (e.g., San José and Casanova 1988), sodars (e.g., Piringer 1988; Beyrich 1997), atmospheric emitted radiance interferometers (AERIs; e.g., Feltz et al. 1998), ground-based lidars (e.g., Menut et al. 1999; Hennemuth and Lammert 2006), airborne lidars (e.g., Nyeki et al. 2000), satellite-borne lidars (e.g., Winker et al. 2007), and more [see, e.g., Seibert et al. (2000) for a review].

\footnotetext{
D Denotes content that is immediately available upon publication as open access.
}

Corresponding author: Dr. Temple R. Lee, temple.lee@noaa.gov
For decades, rawinsonde profiles have been used for obtaining BLDs on a routine basis. Rawinsondes are advantageous in this regard because they are distributed globally. There are currently $\sim 1300$ upper-air stations, including 92 National Weather Service upper-air stations in the United States. Because of their global coverage, rawinsonde observations have been used to construct regional- to global-scale BLD climatologies (e.g., Holzworth 1964; Liu and Liang 2010; Wang and Wang 2014) and to develop climatologies of the quasistationary afternoon BLD over different continents (e.g., Wang and Wang 2014; Lee and Pal 2017). Nonetheless, there remains a significant need for additional BLD observations (e.g., Dabberdt et al. 2005; Hardesty and Hoff 2012; Everett 2018).

Rawinsonde-based approaches for determining BLDs are largely based on the thermodynamic characteristics of the rawinsonde profile, that is, the parcel method (e.g., Holzworth 1964, 1967), the depth of the elevated temperature inversion (e.g., Holzworth 1964), etc.; or using gradients in potential temperature (e.g., Stull 1988; Seidel et al. 2010; Pal 2019), humidity (e.g., von Engeln and Teixeira 2013), or refractivity (e.g., Sokolovskiy et al. 2006) [see, e.g., Seidel et al. (2010) for more details]. Of the techniques that can be used to determine the BLD from rawinsondes, the bulk Richardson $\left(\mathrm{Ri}_{b}\right)$ approach (Vogelezang and Holtslag 1996), which identifies the BLD as the first height at which a critical value, $\mathrm{Ri}_{c}$, is exceeded, has been cited as the preferred approach to determine the BLD 
TABLE 1. Manufacturer-stated accuracy from commonly used rawinsondes for sampling BLDs.

\begin{tabular}{|c|c|c|c|}
\hline Instrument & Temperature accuracy & Relative humidity accuracy & Wind speed accuracy \\
\hline Vaisala radiosonde RS41-SG & $0.3^{\circ} \mathrm{C}(<16 \mathrm{~km}) ; 0.4^{\circ} \mathrm{C}(>16 \mathrm{~km})$ & $4 \%$ & $0.15 \mathrm{~m} \mathrm{~s}^{-1}$ \\
\hline Graw DFM-09 radiosonde & $0.2^{\circ} \mathrm{C}$ & $4 \%$ & - \\
\hline Windsonde & $0.3^{\circ} \mathrm{C}$ & $2.0 \%$ & - \\
\hline iMet-4 radiosonde & $0.5^{\circ} \mathrm{C}(>100 \mathrm{hPa}) ; 1.0^{\circ} \mathrm{C}(<100 \mathrm{hPa})$ & $5 \%$ & $0.5 \mathrm{~m} \mathrm{~s}^{-1}$ \\
\hline iMet-1-ABxn radiosonde & $0.2^{\circ} \mathrm{C}$ & $5 \%$ & - \\
\hline
\end{tabular}

(e.g., Seibert et al. 2000; Seidel et al. 2012). Furthermore, the $\mathrm{Ri}_{b}$ approach has been shown to work well in identifying BLDs from large datasets, for example, those from rawinsondes or from model reanalysis (e.g., Seidel et al. 2012) and for daytime convective boundary layers (Seibert et al. 2000), which are the focus of this study. Another advantage of the $\mathrm{Ri}_{b}$ approach is that the approach calculates the BLD not only as a function of the ABL thermodynamics but also as a function of the ABL kinematics (e.g., Lee and De Wekker 2016), the latter of which is important for highly sheared ABLs (e.g., Conzemius and Fedorovich 2006; Fedorovich and Conzemius 2008; Liu et al. 2018). Additionally, large errors in the measured thermodynamic variables oftentimes coincide with drastic changes in the ABL environment. These changes occur in the surface layer or atop the ABL, especially in the entrainment zone in the presence of shear (Connell and Miller 1995; Fedorovich and Conzemius 2008). Since the surface layer and entrainment zone mainly demarcate the $\mathrm{ABL}$, large errors in thermodynamic variables in these regions can induce significant errors in the estimated BLD.

Regardless of how rawinsonde-based BLDs are determined, BLDs are subject to errors caused by instrument errors. Since the BLD represents the height in the atmosphere to which turbulent mixing processes occur, errors in BLD estimates can have significant impacts for, e.g., air quality and dispersion models, numerical weather prediction (NWP) models, and inversion models in which the BLD is used as a scaling factor within the context of similarity theory (e.g., Stull 1988). Errors in rawinsonde-derived thermodynamic parameters arise for many reasons. For example, temperature and relative humidity (RH) errors occur due to solar radiation heating the sensor and causing a dry RH bias (e.g., Dupont et al. 2020), contamination by surface heating prior to launch, and erroneous temperature and pressure initialization (Connell and Miller 1995). Errors in the $\mathrm{RH}$ arise due to, e.g., the time response of RH sensor of the sondes, the sensor's dependence on temperature gradients, and its time lag for low temperatures (e.g., Dupont et al. 2020). Errors in rawinsonde-derived wind speed may arise due to the pendulum-type motion of the rawinsonde while the rawinsonde is in the ABL or entrainment zone (e.g., MacCready 1965; Wang et al. 2009). Other BLD errors arise by the technique used to compute the BLD itself. For example, Seidel et al. (2012) found BLD errors on the order of a few hundred meters when examining the sensitivity of $\mathrm{Ri}_{c}$ value used, the interpolation of the $\mathrm{Ri}_{b}$ profile to $\mathrm{Ri}_{c}$, and the sounding vertical resolution.

Despite the aforementioned studies on BLD errors, to the best of the authors' knowledge, no known studies have systematically examined the sensitivity of the calculated BLDs to errors in temperature, relative humidity, and horizontal wind measurements made by rawinsondes or have addressed the impact of errors in those variables on BLDs computed using the $\mathrm{Ri}_{b}$ approach. Knowledge of potential errors that may arise is critical for better using BLDs in atmospheric process studies, intercomparisons of BLDs obtained from different platforms, and for other applications including, e.g., air quality and NWP models. For example, Kretschmer et al. (2012) and Pino et al. (2013) reported that the influence of errors in BLD simulations drives large uncertainties in the inverse modeling of regionalscale greenhouse gas fluxes. Tangborn et al. (2020) recently illustrated that BLD assimilation helps improve forecasts of ABL thermodynamic fields.

For most commercially available rawinsondes, the manufacturerreported uncertainties are quite low and are summarized in Table 1. For example, the Vaisala radiosonde RS41-SG has a manufacturer-reported temperature uncertainty of $0.3^{\circ} \mathrm{C}$ for observations below $16 \mathrm{~km}$. The uncertainty in the sounding for measured RH from the RS41-SG is $4 \%$ and is $0.15 \mathrm{~m} \mathrm{~s}^{-1}$ for wind speed. Similar levels of uncertainty are reported for other commercially available radiosondes. Additionally, according to the World Meteorological Organization's (WMO) Observation Systems Capability Analysis and Review Tool (OSCAR), which is a critical component of the WMO Integrated Global Observing System (WIGOS), three different requirement levels have been outlined for using observations in numerical simulations. For instance, the threshold level (i.e., the minimum requirement for the usefulness of observations) requirement for temperature, $\mathrm{RH}$, and wind uncertainties for use in high-resolution NWPs is $3^{\circ} \mathrm{C}, 10 \%$, and $5 \mathrm{~m} \mathrm{~s}^{-1}$, respectively. The breakthrough level (i.e., at which there is a significant improvement of an application and that is optimum from a cost-benefit point of view) requirement for temperature, $\mathrm{RH}$, and wind uncertainties for high-resolution NWPs is $1^{\circ} \mathrm{C}, 5 \%$, and $2 \mathrm{~m} \mathrm{~s}^{-1}$, respectively. However, it is unclear how these errors impact the errors in the BLD estimation.

The aim of this work is to better understand how uncertainties in the thermodynamic and kinematic fields obtained from rawinsondes, coupled with the errors induced by other factors described previously (e.g., radiative effects, the rawinsonde's pendulum-type motion, etc.), affect the calculated BLD. To this end, we examine the sensitivity of BLDs to errors in the temperature, moisture, and wind fields over three sites in the continental United States spanning 35 years.

\section{Data and methods}

We used rawinsonde observations from the Integrated Global Radiosonde Archive (IGRA; e.g., Durre and Yin 2008) 
for the period from 1 January 1981 through 31 December 2015 at three sites in the contiguous United States: Sterling, Virginia; Amarillo, Texas; and Salt Lake City, Utah (Table 2). The use of 35 years of rawinsonde-derived BLDs at sites in three different geographic and climatic regimes (i.e., humid subtropical, tropical and subtropical steppe climate, and warm summer continental at Sterling, Amarillo, and Salt Lake City, respectively, based on the Köppen climate classification; Lee and Pal 2017) allowed for a robust investigation of the biases caused by errors in the rawinsonde-derived thermodynamic and kinematic fields.

The IGRA datasets at each site are mostly complete but there are days with missing data. Because of the missing data, BLDs are able to be computed on $81 \%, 76 \%$, and $74 \%$ of the days at Sterling, Amarillo, and Salt Lake City, respectively. We calculated the BLD by first computing $\mathrm{Ri}_{b}$, whereby bulk gradients are used to approximate local gradients present in the computation of the gradient Richardson number (Ri):

$$
\mathrm{Ri}=\frac{g \frac{\partial \theta_{v}}{\partial z}}{\theta_{v}\left[\left(\frac{\partial u}{\partial z}\right)^{2}+\left(\frac{\partial v}{\partial z}\right)^{2}\right]} \approx \frac{g \Delta \theta_{v} \Delta z}{\theta_{v}\left[(\Delta u)^{2}+(\Delta v)^{2}\right]}
$$

In Eq. (1), $g, \theta_{v}, z, u$ and $v$ represent the gravitational acceleration, virtual potential temperature, sampling height, zonal wind component, and meridional wind component, respectively. When calculating the bulk gradients, we used the surface as the lower bound. Because surface wind speeds are not routinely available in sounding databases like IGRA, following Seidel et al. (2012), we used $0 \mathrm{~m} \mathrm{~s}^{-1}$ for the surface wind speeds. We then followed the approach developed by Lee and De Wekker (2016) to estimate the afternoon BLD. Their approach removes near-surface stable layers, i.e., where $\Delta \overline{\theta_{v}}>0$, from the 0000 UTC IGRA rawinsonde observations to determine the depth of the afternoon boundary layer. We defined the depth of the afternoon boundary layer as the first height at which $\mathrm{Ri}_{b}$ exceeded the critical Richardson number $\mathrm{Ri}_{c}$. Previous studies have used 0.25 for $\mathrm{Ri}_{c}$ (e.g., Vogelezang and Holtslag 1996; Seidel et al. 2012), and sensitivity studies to the choice of $\mathrm{Ri}_{c}$ are reported in, for example, Seidel et al. (2012). Additionally, we defined the BLD as the height of the ABL relative to ground level to remove the effect of terrain elevation on the ABL.

We used the BLDs computed using the above technique to be the "true" BLDs, which we define here as BLD obs $_{\text {, and then }}$ evaluated the impact of height-independent errors in temperature, $\mathrm{RH}$, and the zonal and meridional wind components on the BLD. A systematic evaluation of these hypothetical errors in state variables is important because temperature errors in rawinsondes occur due to the temperature sensor's time constant. These effects become most important in the presence of sharp vertical gradients, such as those occurring atop the ABL and at the secondary inversions beyond the ABL top. In addition to applying errors to the temperature fields, we also applied errors to the rawinsonde-derived $\mathrm{RH}$ and wind fields.

In this work, we explore BLD errors occurring due to errors in not only the thermodynamic fields, but also the kinematic fields. We introduced these errors by applying a constant bias to the measured variable at each height in the rawinsonde
TABLE 2. Station name, latitude, longitude, and elevation for the sites considered in this study.

\begin{tabular}{lrcc}
\hline \hline Station name & Lat $\left({ }^{\circ}\right)$ & Lon $\left(^{\circ}\right)$ & Elev $(\mathrm{m})$ \\
\hline Sterling & 8.98 & -77.48 & 86 \\
Amarillo & 35.23 & -101.70 & 1094 \\
Salt Lake City & 40.77 & -111.97 & 1288 \\
\hline
\end{tabular}

profile and then iterated this for each incremental perturbation in the error range. For example, when we evaluated the impact that a $-3^{\circ} \mathrm{C}$ temperature bias has on the BLD, we subtracted $3^{\circ} \mathrm{C}$ from each temperature measurement at each height in the rawinsonde profile, but did not modify any other variables. We then computed the BLD using the modified profile following the approach described earlier.

We introduced height-independent errors of temperature, $\mathrm{RH}$, and horizontal wind (both zonal and meridional components) throughout the entire rawinsonde profile. Considering height-independent errors allows us to examine the impact of both random errors and instrumental errors that persist throughout the lower troposphere (i.e., 5-6 km AGL) but may vary among soundings (WMO 2017, 2018). The introduction of height-dependent errors would cause additional uncertainty, for example, in rawinsonde profiles containing multiple elevated inversions. Additionally, height-dependent errors based on analytical functions can be prone to errors in the surfacelayer temperature structure. Furthermore, the development of analytical functions for errors in the thermodynamic variables following the physics of the real ABL is a highly challenging task. We acknowledge that one of the shortcomings of our approach is that we cannot examine the impact of vertical resolutions and smoothing of the thermodynamic and kinematic variables, but acknowledge that the investigation of errors in sounding vertical resolution has already been conducted by Seidel et al. (2012).

For the analyses presented, we introduced the WMOspecified observation-inclusion thresholds as our error ranges (cf. section 1), which are $\pm 3^{\circ} \mathrm{C}, \pm 10 \%$, and $\pm 5 \mathrm{~m} \mathrm{~s}^{-1}$ for temperature, $\mathrm{RH}$, and wind speed, respectively. Also, these levels are the threshold requirements for including observations in high-resolution NWP as mentioned before. To illustrate how we investigated the impact of errors in temperature, $\mathrm{RH}$, and wind, we used the rawinsonde profile obtained on 11 January 2015 profile at Amarillo. To examine the sensitivity of computed BLDs to errors in temperature, we performed sensitivity tests over the range from $-3^{\circ}$ to $+3^{\circ} \mathrm{C}$ at $0.1^{\circ} \mathrm{C}$ increments. When introducing these perturbations to the temperature fields, the humidity and wind fields were not changed. We then used the perturbed temperatures to compute $\theta_{v}$ and calculated the BLD using Eq. (1). Doing so yielded 60 different $\mathrm{Ri}_{b}$ profiles, and thus 60 different BLDs, as illustrated in Figs. 1a and 1b. For instance, the blue region in Fig. 1a represents errors in temperature profile around the "true" profile; however, the vertical spread of the red line indicating ABL top was negligible. Thus, in this instance, modifying the temperature profile by $\pm 3^{\circ} \mathrm{C}$ had a negligible impact on the BLD. However, it remains unclear how different temperature 

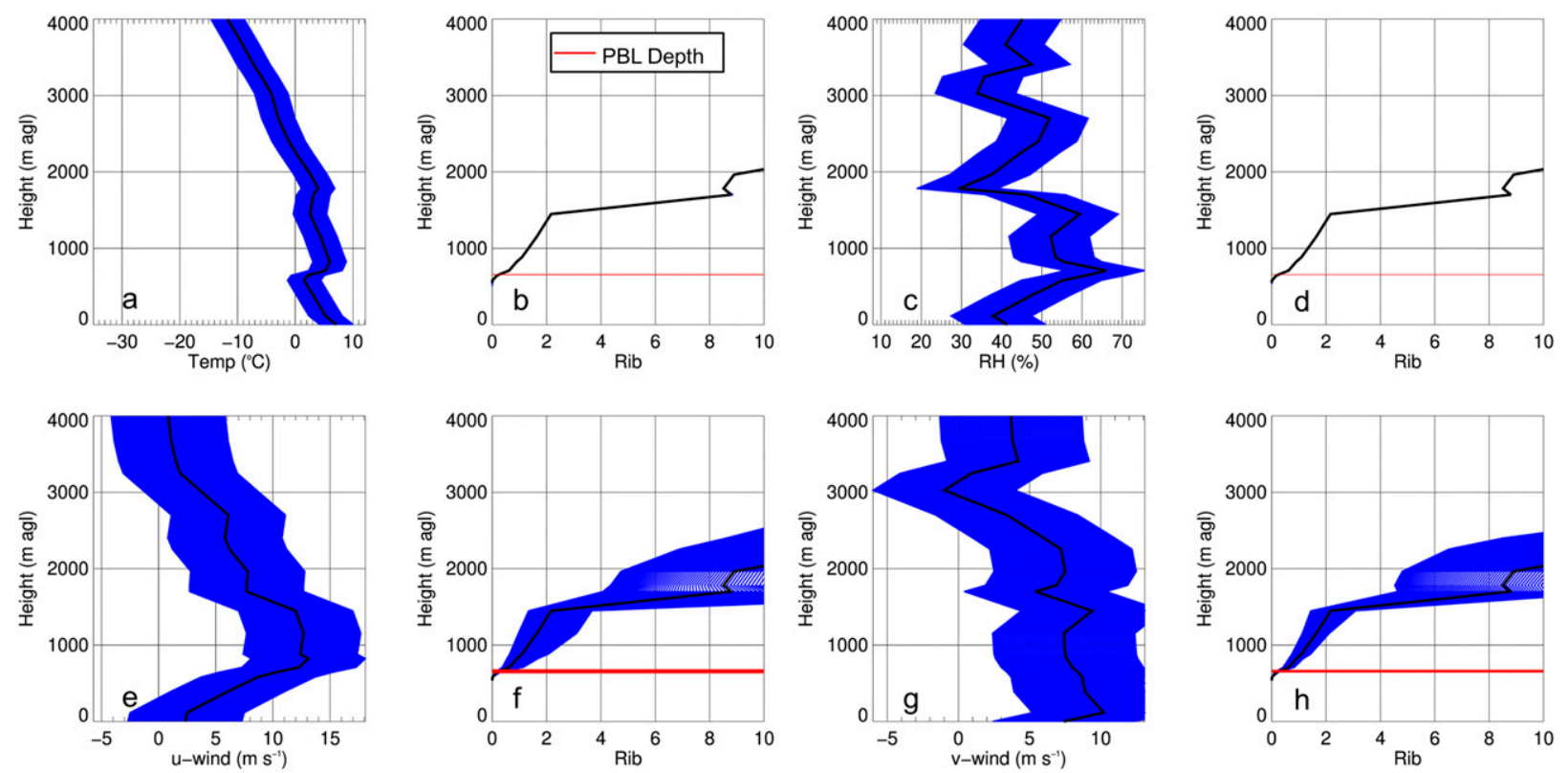

FIG. 1. Sensitivity test, using the 0000 UTC 11 Jan 2015 sounding at Amarillo on the impact of (a) temperature biases (blue lines illustrate the error range) on (b) the $\mathrm{Ri}_{b}$ profile (blue lines; not visible because effect is negligible) and the BLD (red lines; again the effect is negligible). (c) The impact of RH errors on (d) the $\mathrm{Ri}_{b}$ profile and BLD. The same analysis is shown for the effect of (e),(f) the $u$ wind component and $(\mathrm{g}),(\mathrm{h}) v$ wind component. The black lines show the observed rawinsonde profile for each quantity on the $x$ axis [identical in (b), (d), (f), and (h)].

profiles with imposed height-dependent errors, different temperature inversion strengths, entrainment zone structures, different time scales of sensors, different rawinsonde ascent rates, and different $A B L$ regimes under various meteorological conditions, etc. impact errors in retrieved BLDs computed using the $\mathrm{Ri}_{b}$ approach. Thus, one needs to examine errors for many profiles, which we do in the next section.

We used the same rawinsonde profile obtained on 11 January 2015 profile at Amarillo and repeated the sensitivity test for RH, keeping the temperature and wind fields constant, and performed this test over the range from $-10 \%$ to $+10 \%$ at $0.2 \%$ increments. The perturbed values for $\mathrm{RH}$ were used to compute the specific humidity, $q$, which was then used to calculate $\theta_{v}$ and to compute the BLD following Eq. (1). The impacts of changing RH are illustrated in Figs. 1c and 1d. As with temperature, varying $\mathrm{RH}$ by $\pm 10 \%$ did not significantly impact the BLD on this particular day.

We performed similar sensitivity tests for the zonal and meridional wind components over the range from -5 to $+5 \mathrm{~m} \mathrm{~s}^{-1}$ at $0.1 \mathrm{~m} \mathrm{~s}^{-1}$ increments using these perturbed values in Eq. (1) while keeping the temperature and moisture fields constant. The impact of varying $u$ on the $\mathrm{Ri}_{b}$ profiles is illustrated in Figs. 1e and 1f, and the impact of varying $v$ is shown in Figs. $1 \mathrm{~g}$ and $1 \mathrm{~h}$. On this particular day, variations in $u$ and $v$ had a more significant impact than varying the thermodynamic quantities on the $\mathrm{Ri}_{b}$ profiles and thus led to BLD errors, which we define as $\delta$ BLD, of $\sim 100 \mathrm{~m}$.

The results obtained using the 11 January 2015 profile at Amarillo help illustrate the methodology of the impact of errors in the state variables on the estimation of BLDs for a single case. However, it remains unclear how the impact of similar errors emerges for a range of ABL regimes throughout the year under different meteorological conditions (e.g., different seasons). A more detailed analysis on the impact of these errors allows for more generalized conclusions to be drawn and is the focus of the next section.

\section{Results and discussion}

\section{a. Errors in rawinsonde-derived temperature fields}

One of the driving factors behind this work is the application of the results to evaluate errors in BLD measurements for different ABL applications including NWP and BLD intercomparison efforts. To investigate how these errors affect BLD, we plotted $\delta$ BLD as a function of the temperature error for all profiles, as was done in the single example profile shown in Fig. 1 . We then sorted $\delta$ BLD into $10-\mathrm{m}$ bins and determined the number of occurrences $N$ within each of these bins to illustrate the spread of $\delta$ BLD due to imposed temperature errors. Because the number of cases per bin varied significantly, we report $\log _{10}(N)$, rather than the actual number of occurrences. Additionally, we calculated the 2.5 th, 5th, 10th, 50th, 90th, 95th, and 97.5th percentiles of $\delta \mathrm{BLD}$ to further illustrate the range of $\delta \mathrm{BLD}$ as a function of errors in the rawinsonde-derived thermodynamic and kinematic fields.

We found that the $\delta$ BLD from Sterling, Amarillo, and Salt Lake City behaved similarly in terms of their respective biases when inducing an error to the rawinsonde's temperature measurements and then computing the BLDs (Fig. 2). 
a

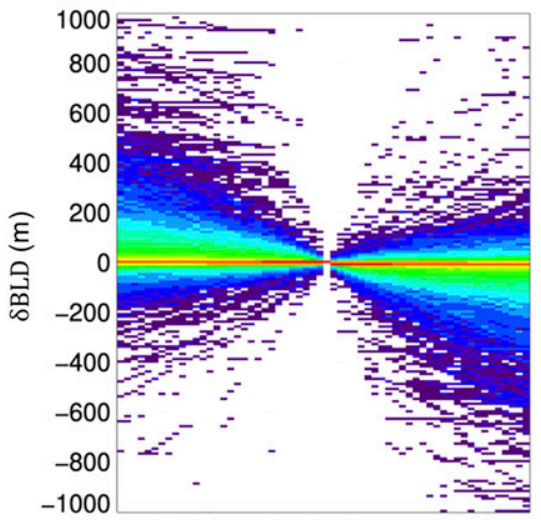

C
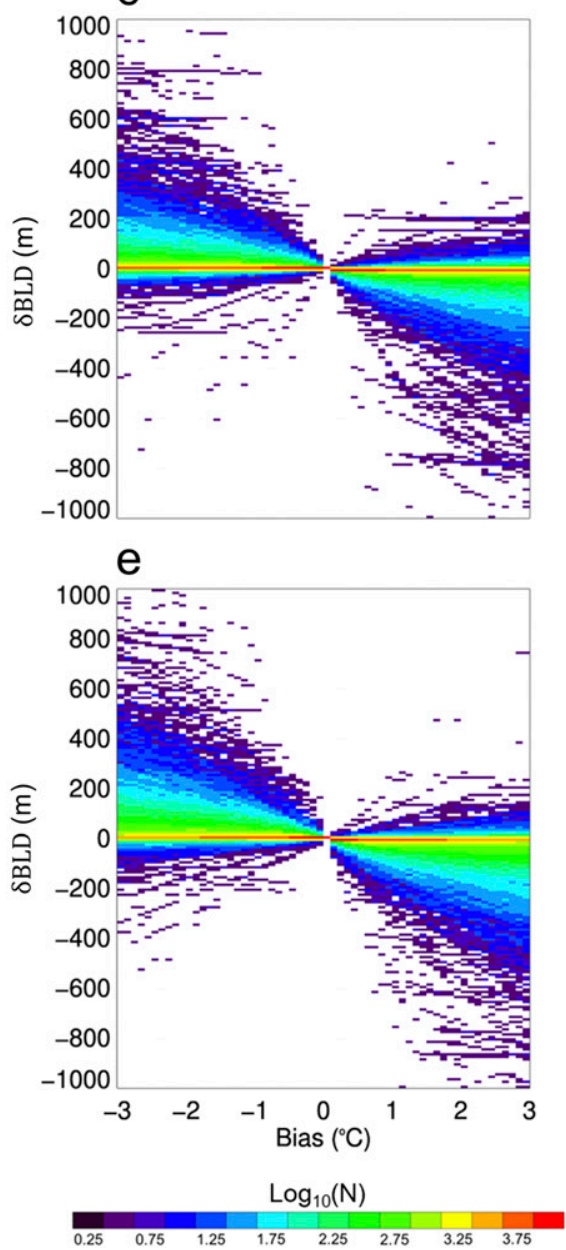

b
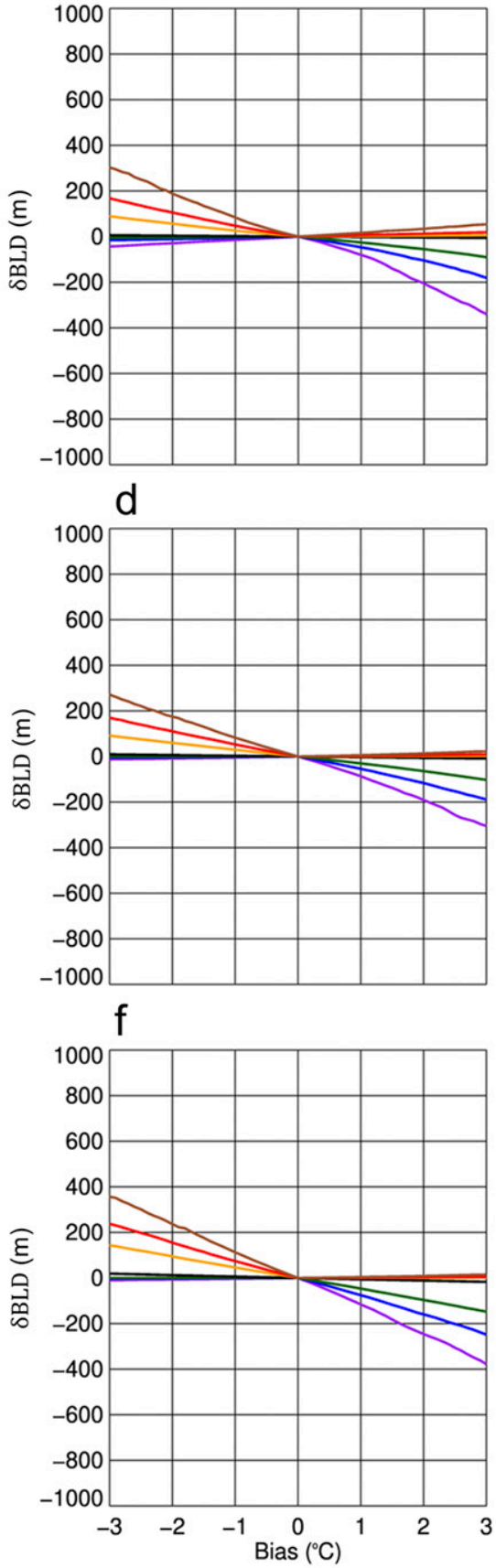

Percentile

$\overline{2.5} \frac{5}{10} \overline{50} \frac{}{90} \overline{95} \quad \overline{97.5}$

FIG. 2. Dependence of $\delta \mathrm{BLD}$ on temperature biases from $-3^{\circ} \mathrm{C}$ to $+3^{\circ} \mathrm{C}$ at (a) Sterling, (c) Amarillo, and (e) Salt Lake City. The distribution is shown in $\log _{10}(N)$ scale (see color bar range from 0.25 to 3.75). Here, $N$ is the number of cases each bin, wherein the data are binned every $10 \mathrm{~m}$ and every $0.1^{\circ} \mathrm{C}$. (b), (d), and (f) show the percentiles at each of the sites, respectively; purple, blue, green, black, orange, red, and brown correspond to the 2.5 th, 5 th, 10th, 50th, 90th, 95th, and 97.5th percentiles, respectively. 
These results indicate that negative and positive biases in temperature mainly yield positive and negative $\delta B L D$, respectively. In the extreme case of a $\pm 3^{\circ} \mathrm{C}$ bias in temperature, BLD errors were $\pm 300 \mathrm{~m}$ at the 2.5 th and 97.5 th percentiles and were similar across all sites. We also noted a few instances at all sites in which $\delta$ BLD were significantly high, approaching $1000 \mathrm{~m}$ in a few circumstances (i.e., Figs. 2a,c,e), and we found that the BLD errors do not linearly vary from negative to positive biases. Thus, a simple analytical correction for these results cannot be applied.

The relationship between temperature biases and $\delta \mathrm{BLD}$ initially appears counterintuitive, since one would expect a positive temperature bias to increase the BLD. However, this is not consistently the case because of how the errors in temperature are propagated to compute $\mathrm{Ri}_{b}$. When keeping all other variables constant, a change in temperature results in a change to the saturation vapor pressure $e_{s}$. We computed $e_{s}$ using the following equation from Magnus (1844), where $T$ is the air temperature:

$$
e_{s}=6.1078 \exp \left(\frac{17.269 T}{T+237.3}\right)
$$

Because we are keeping $\mathrm{RH}$ constant, changing $e_{s}$ results in a change in the actual vapor pressure $e$. The change to $e$ results in differences to $q$, thereby modifying not only $\theta_{v}$ but, more important, modifying the $\theta_{v}$ gradient, affecting $\mathrm{Ri}_{b}$ and thus the computed BLDs.

\section{b. Errors in rawinsonde-derived relative humidity fields}

We performed similar analyses for $\mathrm{RH}$ as for temperature and found that $\delta \mathrm{BLD}$ was larger for $\mathrm{RH}$ errors than for temperature errors (Fig. 3). In the extreme scenario of a $-10 \% \mathrm{RH}$ bias, errors in BLD were up to 500-700 $\mathrm{m}$ at Sterling, Amarillo, and Salt Lake City. In contrast, a $+10 \% \mathrm{RH}$ bias resulted in errors at the 97.5th percentile of around $500 \mathrm{~m}$ at Amarillo and Salt Lake City but around $400 \mathrm{~m}$ at Sterling. As was the case with temperature biases, there were instances at all three sites in which $\delta$ BLD approached $1000 \mathrm{~m}$ even for relatively small perturbations to the RH field. A similar argument can be made for the relationship between $\delta \mathrm{BLD}$ and $\mathrm{RH}$ bias. Changes in $\mathrm{RH}$ result in changes to $e$, causing $q$ to change. The change in $q$ affected $\theta_{v}$, thus affecting the $\theta_{v}$ gradient, which altered $\mathrm{Ri}_{b}$ and the computed BLD.

Errors in rawinsonde-derived $\mathrm{RH}$ measurements of $5 \%-$ $10 \%$ in the daytime $\mathrm{ABL}$ have been reported in, e.g., Dupont et al. (2020), who attributed RH errors in the lowest $2 \mathrm{~km}$ of the ABL to errors in temperature between the temperature measured by the RH sensor itself and the actual air temperature observed by the rawinsonde's temperature sensor. Furthermore, the manufacturer-stated accuracies of many commercially available rawinsondes are on the order of $4 \%-5 \%$ (cf. Table 1 ), which does not include, for example, considerations of the sensor's time response when the rawinsonde is ascending through rapidly changing moisture regimes such as those that can occur atop the ABL (e.g., von Engeln and Teixeira 2013). As we show here, RH errors of even $4 \%-5 \%$ can have a significant impact on the calculated BLD.

\section{c. Errors in rawinsonde-derived kinematic fields}

So far, we have focused on the impact of errors in the rawinsonde-derived thermodynamic measurements on $\delta \mathrm{BLD}$, which are important for ABLs governed by buoyancy-driven turbulence. However, we have not yet considered the impact of errors in the rawinsonde-derived kinematic fields. Knowledge of the potential impacts of errors in these fields is especially important for highly sheared ABLs (e.g., Conzemius and Fedorovich 2006; Fedorovich and Conzemius 2008; Liu et al. 2018). Additionally, it has been found that frontal environments pose additional challenges characterizing BLD variability when temperature, moisture and wind change drastically before and after frontal passages (e.g., Boulte et al. 2010; Clark et al. 2020). We found nontrivial BLD errors across all stations when introducing perturbations to the $u$ and $v$ wind components as compared with the thermodynamic quantities. At Sterling, a $-5 \mathrm{~m} \mathrm{~s}^{-1}$ bias in the $u$ wind component resulted in $\delta$ BLD of about $900 \mathrm{~m}$ at the 2.5 th percentile, and there were a few cases in which $\delta$ BLD exceed $1000 \mathrm{~m}$ (Fig. 4). Errors were smaller at Amarillo and Salt Lake City than at Sterling, but $\delta$ BLD was still at times $>500 \mathrm{~m}$.

The findings for errors in the $u$ wind component were largely consistent with those for the $v$ wind component (Fig. 5), as $\delta$ BLD was generally between -500 and $+500 \mathrm{~m}$. Unlike for temperature and moisture, there was no clear tendency between negative biases and positive biases, as $\delta$ BLD was similar for the $u$ and $v$ wind components. As a result, the median $\delta \mathrm{BLD}$ was $\sim 0 \mathrm{~m}$. Knowledge of wind-induced errors on BLD is important because, as noted in section 1 and summarized here, the pendulum-like motion of the rawinsonde during its ascent through the ABL can induce errors in the kinematic fields (e.g., MacCready 1965; Wang et al. 2009).

\section{d. Dependence of $\delta B L D$ on $B L D$ regimes}

From the analyses presented in the previous sections of introducing errors to rawinsonde-derived thermodynamic and kinematic fields and then computing the BLD, we conclude that $\delta \mathrm{BLD}$ as a function of the biases that we introduced is similar across all three sites. So far, we have not discussed the different regimes in which $\delta$ BLD is largest. Doing so is essential because of the different types of BLD variabilities that are routinely observed. For example, shallow and deep BLDs can occur both in the cold and warm seasons (e.g., Liu and Liang 2010; Seidel et al. 2012; Lee and Pal 2017), spatial BLD variability exists for terrain-following versus terrainindependent ABL regimes (e.g., Kalthoff et al. 1998; Kossmann et al. 1998; Lee and De Wekker 2016; Pal et al. 2016), and both shallow and deep BLD regimes can be present during the early-morning (e.g., Lenschow et al. 1979) and early-evening (e.g., Acevedo and Fitzjarrald 2001) transition periods. Furthermore, there are different $\mathrm{ABL}$ regimes in which deep versus shallow BLDs prevail, i.e., stable ABLs versus convective ABLs (e.g., Stull 1988), sheared versus nonsheared ABLs (e.g., Fedorovich and Conzemius 2008), cloud-topped versus cloud-free ABLs (e.g., Garratt 1994), moist ABLs versus entrainment-drying ABLs (e.g., Stull 1988), quasi-stationary versus growing ABLs (e.g., Pal and Haeffelin 2015; 

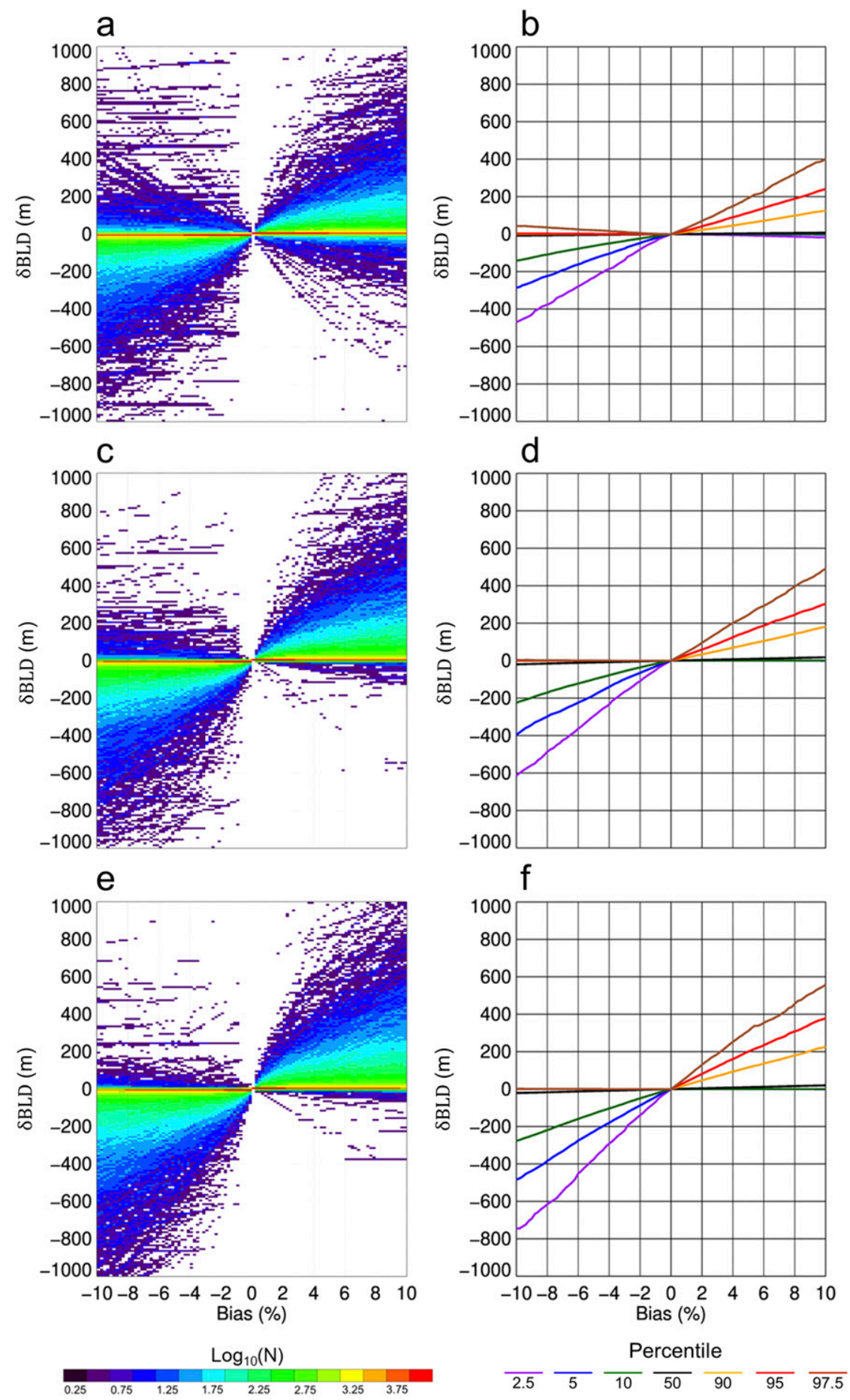

FIG. 3. As in Fig. 2, but for relative humidity. Data are binned every $10 \mathrm{~m}$ and every $0.2 \%$.

Muppa et al. 2016), ABLs over land versus ABLs over water (e.g., Garratt 1994), and rural versus urban ABLs (e.g., Pal et al. 2012).

Because of the many causes of BLD variability, it is critical to investigate the uncertainties in BLDs for shallow versus deep ABLs. To investigate the relationship between $\delta$ BLD and
$\mathrm{BLD}_{\mathrm{ob}}$, we sorted $\mathrm{BLD}_{\mathrm{obs}}$ into 500 -m bins and calculated the BLD errors caused by temperature biases. Here we selected temperature biases $< \pm 3.0^{\circ} \mathrm{C}$ although we note that our results are not significantly affected by our choice of this threshold, as the trends are present for other thresholds as well based on sensitivity tests using thresholds of $\pm 0.5^{\circ}$ and $\pm 1.0^{\circ} \mathrm{C}$ 

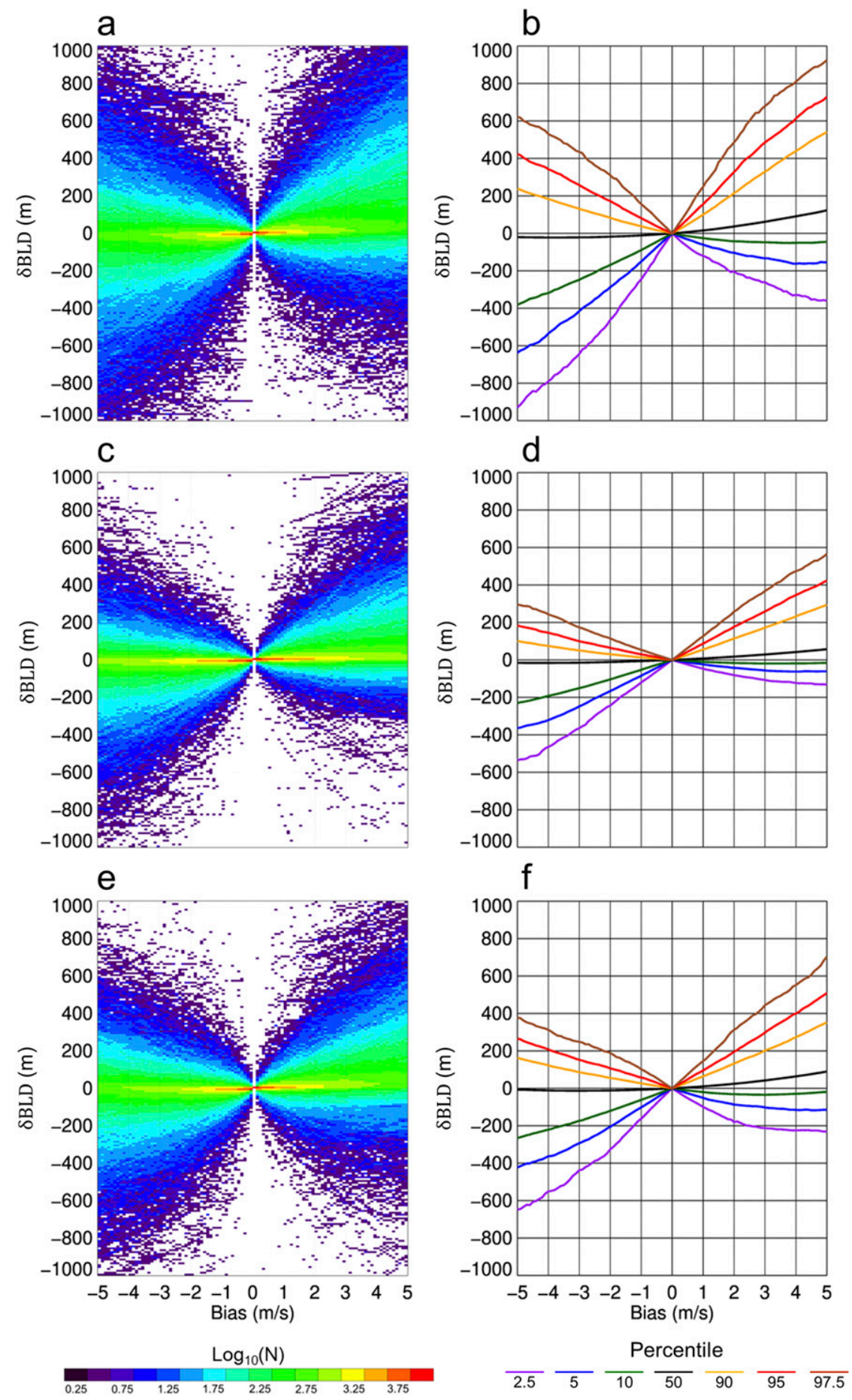

FIG. 4. As in Fig. 2, but for the zonal (i.e., $u$ ) wind component. Data are binned every $10 \mathrm{~m}$ and every $0.1 \mathrm{~m} \mathrm{~s}^{-1}$.

(not shown). When using a threshold of $\pm 3^{\circ} \mathrm{C}$, we found only very small values of $\delta$ BLD for shallow BLDs (i.e., those $\sim 500 \mathrm{~m} \mathrm{AGL}$ ). For deep BLDs (i.e., those >3000 m AGL), $\delta \mathrm{BLD}$ ranges from about -300 to about $125 \mathrm{~m}$ at the 2.5 th and 97.5 th percentiles, respectively, as is shown in the example from Amarillo (Fig. 6a). The relationship between $\delta$ BLD and BLD is consistent at Sterling and Salt Lake City (not shown).

We found a similar increase in $\delta$ BLD as a function of BLD when selecting $\mathrm{RH}$ biases $< \pm 10 \%$, although the magnitude of 

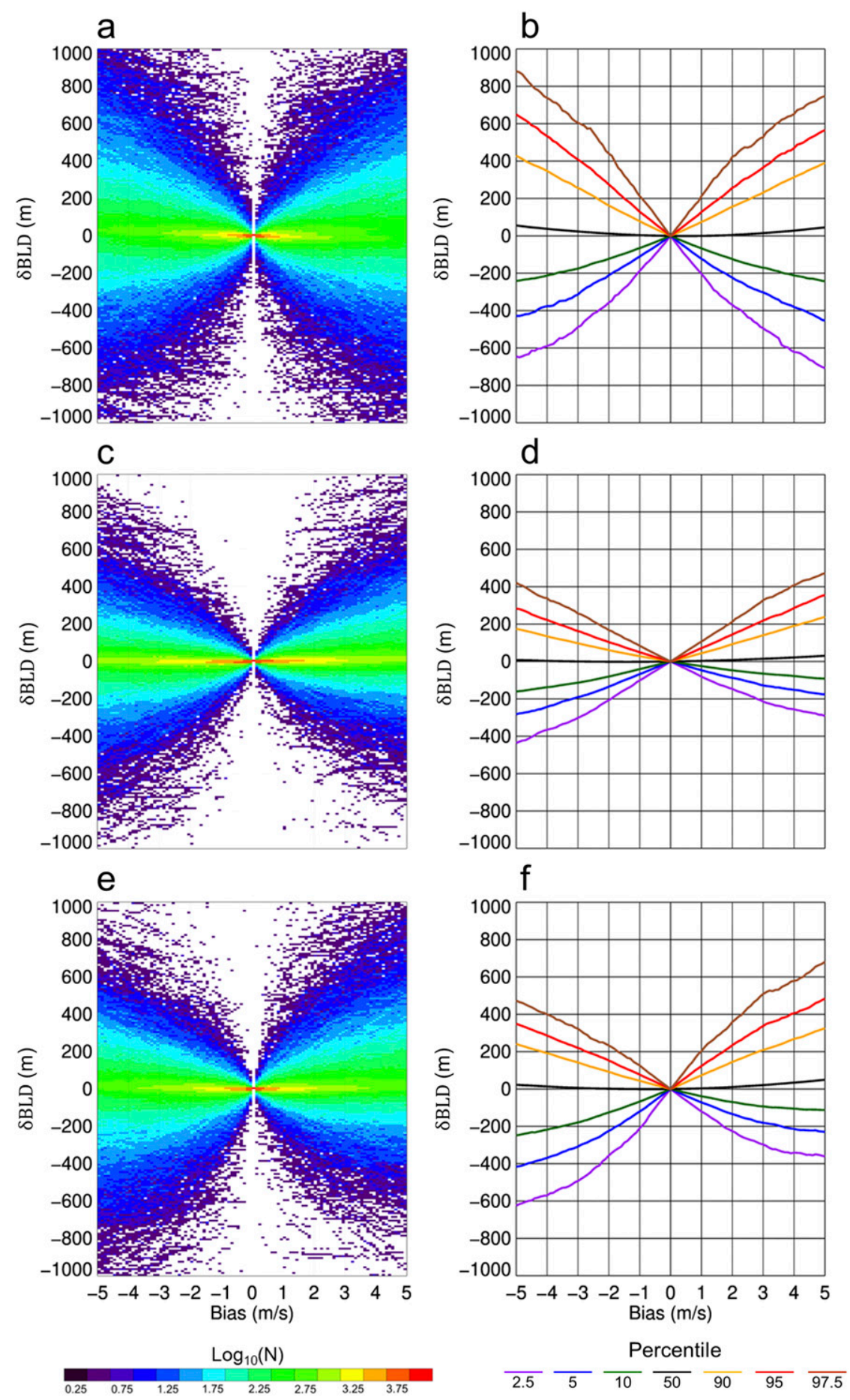

FIG. 5. As in Fig. 2, but for the meridional (i.e., $v$ ) wind component. Data are binned every $10 \mathrm{~m}$ and every $0.1 \mathrm{~m} \mathrm{~s}^{-1}$.

the errors is larger for deeper BLDs (Fig. 6b). For example, BLDs exceeding $3000 \mathrm{~m}$ have errors at the 2.5th and 97.5th percentiles ranging from -500 to $-600 \mathrm{~m}$ and from +200 to $+300 \mathrm{~m}$, respectively. Sensitivity results for RH biases $< \pm 2.5 \%$ and $< \pm 5 \%$ (not shown) yielded similar conclusions on the relationship between $\delta \mathrm{BLD}$ and BLD, and this relationship is consistent with Sterling and Salt Lake City (not shown).

The relationship between $\delta$ BLD and BLD is less clear when selecting $u$ - and $v$-wind biases $< \pm 5 \mathrm{~m} \mathrm{~s}^{-1}$ and plotting $\delta$ BLD as a function of $\mathrm{BLD}_{\text {obs }}$ (Figs. $\left.6 \mathrm{c}, \mathrm{d}\right)$. In both cases, we found a 
a

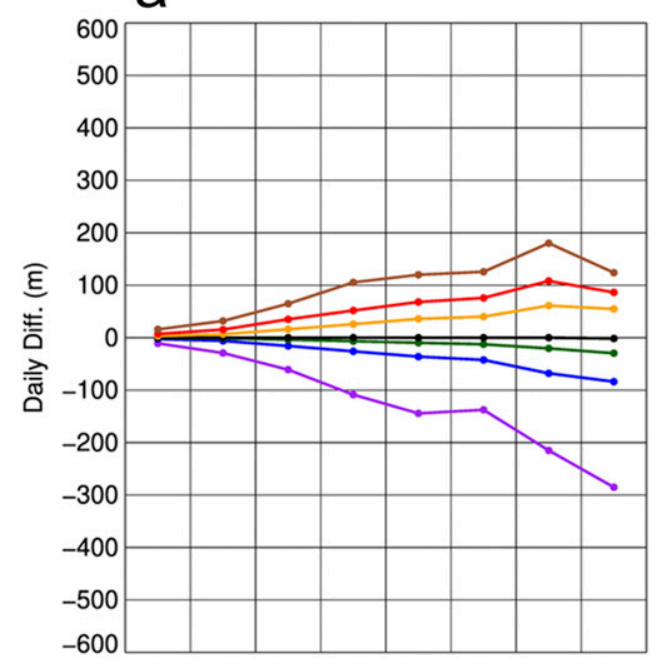

C

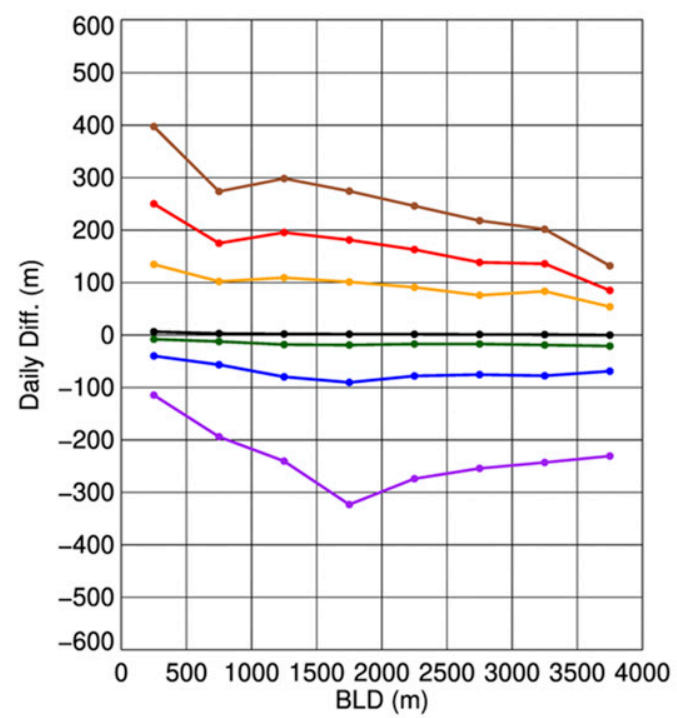

b
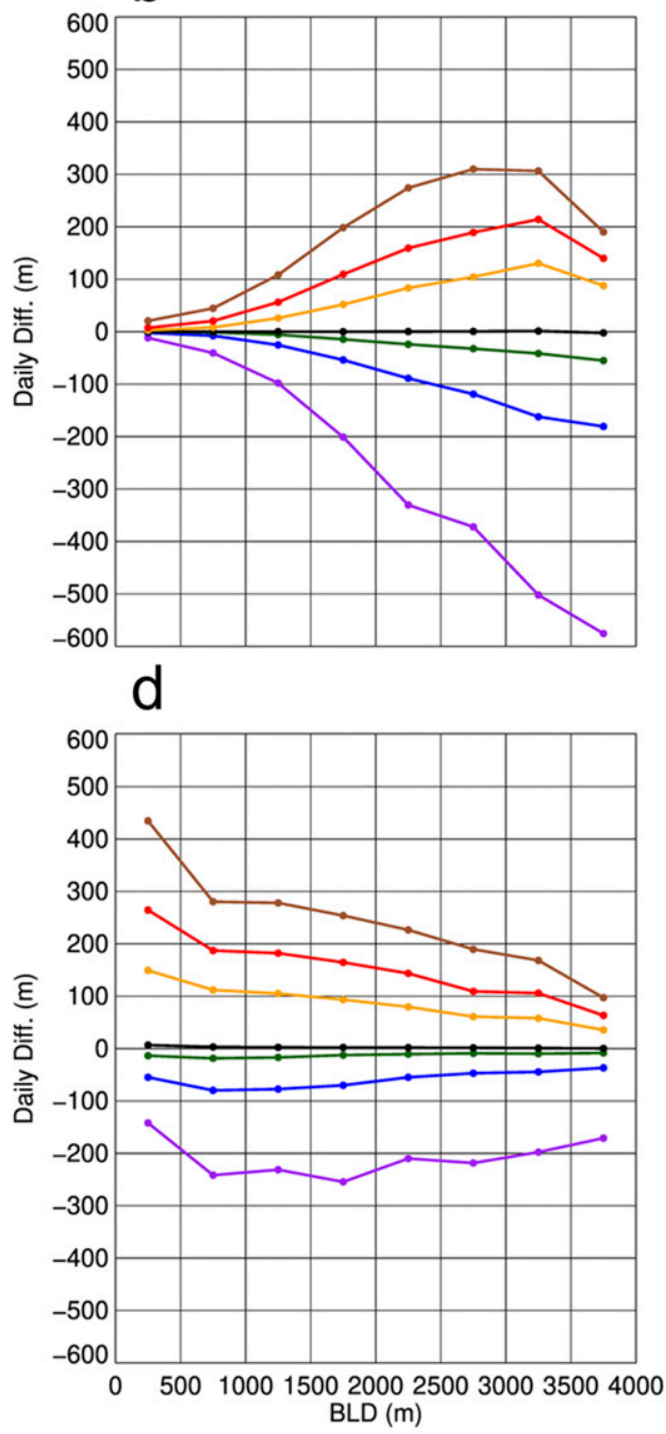

Percentile

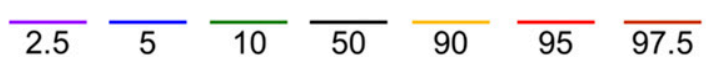

FIG. 6. The $\delta \mathrm{BLD}$ as a function of BLD at Amarillo for (a) temperature biases $< \pm 3^{\circ} \mathrm{C}$, (b) relative humidity biases $< \pm 10 \%$, (c) $u$-wind-component biases $< \pm 5 \mathrm{~m} \mathrm{~s}^{-1}$, and (d) $v$-wind-component biases $< \pm 5 \mathrm{~m} \mathrm{~s}^{-1}$. Purple, blue, green, black, orange, red, and brown lines correspond to the 2.5th, 5th, 10th, 50th, 90th, 95th, and 97.5th percentiles, respectively. BLD is binned into 500-m bins.

decrease in $\delta$ BLD as a function of BLD. For example, BLDs that are $\sim 500 \mathrm{~m}$ have a $\delta \mathrm{BLD}$ that ranges from $\sim-100$ to $+400 \mathrm{~m}$ at the 2.5 th and 97.5 th percentiles, respectively, whereas BLDs that are $\sim 3500 \mathrm{~m}$ have a $\delta \mathrm{BLD}$ that ranges from $\sim-200$ to $+150 \mathrm{~m}$ at the 2.5 th and 97.5 th percentiles, respectively. Sensitivity tests for $u$ - and $v$-wind biases $< \pm 1$ and $< \pm 3 \mathrm{~m} \mathrm{~s}^{-1}$, as well as analyses of the other two sites, yielded similar conclusions regarding the relationship between $\delta$ BLD and BLD. In the future, we plan to extend these analyses by selecting sheared versus nonsheared ABL regimes and will investigate the dependencies of $u$ and $v$ errors on $\delta \mathrm{BLD}$.

\section{e. Combined effects of errors in the thermodynamic and kinematic fields on $\delta B L D$}

So far, we have considered the effects of individual factors on the estimated BLDs separately. However, it is also important to consider the cumulative impact of different factors (i.e., simultaneous uncertainties of temperature, $\mathrm{RH}$, and horizontal wind) on the estimated boundary layer depth. To examine the 


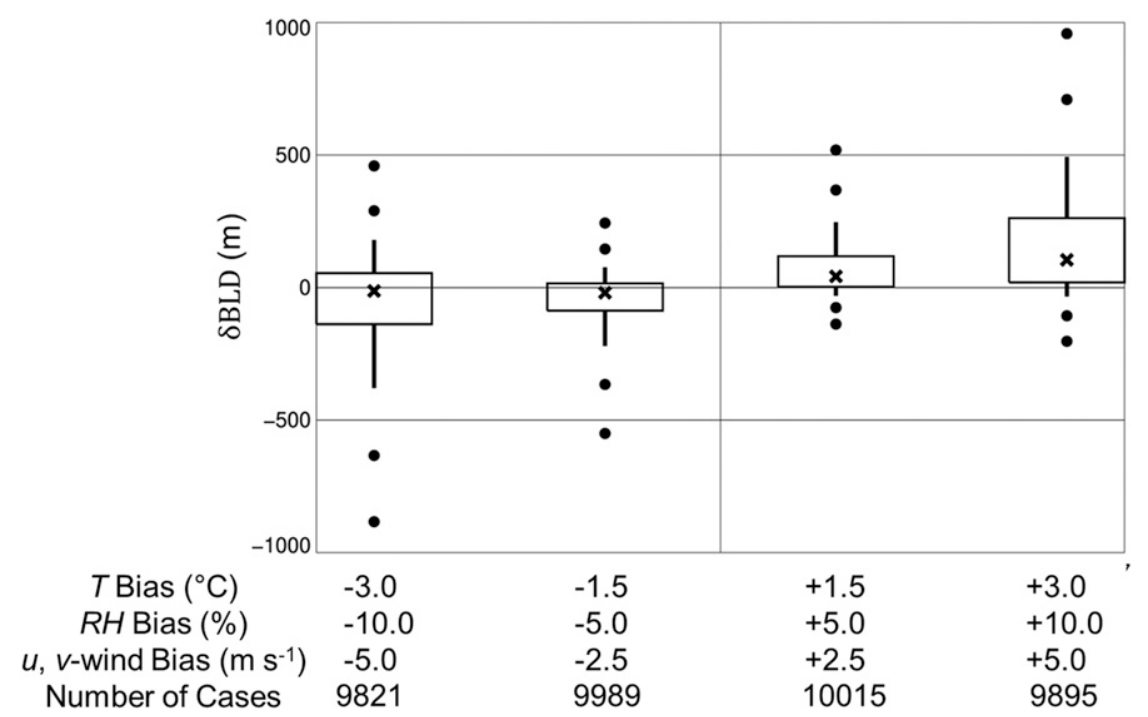

FIG. 7. Box-and-whisker plot illustrating the combined effects of biases in temperature, humidity, and wind on $\delta$ BLD at Amarillo. The boxes encompass the 25 th-75th percentiles, the $\mathrm{x}$ indicates the 50th percentile, and the whiskers extend out to the 10th and 90th percentiles. Filled circles represent the 2.5th, 5th, 95th, and 97.5th percentiles. The number of cases in each category is shown at the bottom of the figure.

combined effect of different factors on the estimated BLDs, we simultaneously perturbed the temperature, humidity, and wind fields over the entire profile and then recalculated the BLDs as presented via box-and-whisker analyses of $\delta$ BLD for a range of biases in $T, \mathrm{RH}$, and wind components (Fig. 7). We found that, in the extreme cases (i.e., a temperature, $\mathrm{RH}, u$-wind, and $v$-wind bias of $-3^{\circ} \mathrm{C},-10 \%,-5$, and $-5 \mathrm{~m} \mathrm{~s}^{-1}$, respectively), $\delta \mathrm{BLD}$ ranged from about $-900 \mathrm{~m}$ at the 2.5 th percentile to around $+500 \mathrm{~m}$ at the 97.5 th percentile, as shown in the example from Amarillo (Fig. 7). At the other extreme (i.e., a temperature, $\mathrm{RH}, u$-wind, and $v$-wind bias of $+3^{\circ} \mathrm{C},+10 \%,+5$, and $+5 \mathrm{~m} \mathrm{~s}^{-1}$, respectively), $\delta$ BLD ranged from about -200 to $1000 \mathrm{~m}$ at the 2.5 th and 97.5 th percentiles, respectively. These conclusions were consistent at Sterling and Salt Lake City (not shown). Since this is the first time this has been investigated, we are unable to place these results into the context of other studies. Notwithstanding, it became evident once again that the impact of errors of the horizontal wind components (i.e., kinematics) on $\delta \mathrm{BLD}$ is substantial.

\section{f. Mean biases in the rawinsonde-derived thermodynamic and kinematic fields}

Averaging the biases across all three sites also allows for us to quantify the expected errors given a known bias in temperature, RH, and wind obtained from rawinsondes. To this end we report the mean $\delta \mathrm{BLD}$, that is, $\overline{\delta \mathrm{BLD}}$, at the 2.5 th and 97.5 th percentiles, as $95 \%$ of all cases will fall within these bounds. $\overline{\delta \mathrm{BLD}}$ for the thermodynamic fields is summarized in Tables 3 and 4 and highlights the nontrivial errors associated with biased moisture measurements as $\overline{\delta \text { BLD }}$ was 609 and $483 \mathrm{~m}$ for a $-10 \%$ and $+10 \% \mathrm{RH}$ bias, respectively. Computing $\overline{\delta \mathrm{BLD}}$ at the 2.5 th and 97.5 th percentiles also allows us to illustrate the errors present in the $u$ and $v$ wind components
(Table 5), which, when averaged across all three stations, range from -705 to $432 \mathrm{~m}$ (from -569 to $591 \mathrm{~m}$ ) for a $-5 \mathrm{~m} \mathrm{~s}^{-1}$ in the $u(v)$ wind component and from -241 to $731 \mathrm{~m}$ (from -453 to $634 \mathrm{~m})$ for $\mathrm{a}+5 \mathrm{~m} \mathrm{~s}^{-1}$ in the $u(v)$ wind component.

\section{g. Comparison with previous studies}

Our results indicate errors in BLD measurements were similar across different geographic regions and climate regimes. Accordingly, we conclude that our approach for BLD error characterization is universal and can be implied to other sites. Thus, the results provide information on the magnitude of errors in BLD caused by errors in rawinsonde-derived temperature, moisture, and wind fields. We show that these

TABLE 3. Mean 2.5th and 97.5th percentiles of BLD differences over all stations for temperature biases, ranging from $-3.0^{\circ}$ to $3.0^{\circ} \mathrm{C}$ in increments of $0.5^{\circ} \mathrm{C}$.

\begin{tabular}{ccc}
\hline \hline$T$ bias $\left({ }^{\circ} \mathrm{C}\right)$ & $\begin{array}{c}\overline{\delta B L D}, 2.5 \text { th } \\
\text { percentile }(\mathrm{m})\end{array}$ & $\begin{array}{c}\overline{\delta \mathrm{BLD}}, 97.5 \text { th } \\
\text { percentile }(\mathrm{m})\end{array}$ \\
\hline-3.0 & -22.0 & 310.2 \\
-2.5 & -18.3 & 257.5 \\
-2.0 & -14.9 & 199.8 \\
-1.5 & -11.2 & 146.8 \\
-1.0 & -7.6 & 92.9 \\
-0.5 & -3.9 & 43.8 \\
0.0 & 0.0 & 0.0 \\
0.5 & -44.5 & 4.2 \\
1.0 & -94.3 & 8.6 \\
1.5 & -153.8 & 13.8 \\
2.0 & -214.0 & 18.8 \\
2.5 & -279.1 & 24.5 \\
3.0 & -341.1 & 30.3 \\
\hline
\end{tabular}


TABLE 4. Mean 2.5th and 97.5th percentiles of BLD differences over all stations for RH biases, ranging from $-10.0 \%$ to $10.0 \%$ in increments of $1.0 \%$.

\begin{tabular}{ccc}
\hline \hline & $\begin{array}{c}\overline{\delta B L D}, 2.5 \text { th } \\
\text { percentile }(\mathrm{m})\end{array}$ & $\begin{array}{c}\overline{\delta \mathrm{BLD}}, 97.5 \text { th } \\
\text { percentile }(\mathrm{m})\end{array}$ \\
\hline-10.0 & -609.1 & 16.5 \\
-9.0 & -559.2 & 15.0 \\
-8.0 & -493.1 & 12.9 \\
-7.0 & -432.8 & 11.1 \\
-6.0 & -364.5 & 8.9 \\
-5.0 & -301.1 & 7.4 \\
-4.0 & -237.3 & 5.8 \\
-3.0 & -175.3 & 4.1 \\
-2.0 & -110.5 & 2.2 \\
-1.0 & -52.7 & 0.7 \\
0.0 & 0.0 & 0.0 \\
1.0 & -0.4 & 47.0 \\
2.0 & -0.9 & 98.2 \\
3.0 & -1.3 & 147.7 \\
4.0 & -1.8 & 200.5 \\
5.0 & -2.4 & 248.7 \\
6.0 & -3.2 & 290.6 \\
7.0 & -4.0 & 337.8 \\
8.0 & -4.8 & 390.8 \\
9.0 & -5.2 & 438.1 \\
10.0 & -6.2 & 482.9 \\
\hline
\end{tabular}

errors can be nontrivial. The errors that we identify are of similar magnitude to those found by Seidel et al. (2012) in their study of the sensitivity of BLDs computed using the $\mathrm{Ri}_{b}$ approach to several different metrics. In their study, they also used IGRA-derived rawinsonde observations and examined the sensitivity of BLDs computed using the $\mathrm{Ri}_{b}$ approach to 1) the choice of $\mathrm{Ri}_{c}, 2$ ) errors caused by using $0 \mathrm{~m} \mathrm{~s}^{-1}$ for the surface wind speeds, 3 ) interpolation of the $\mathrm{Ri}_{b}$ profile to $\mathrm{Ri}_{c}$, and 4) the sounding vertical resolution. The choice of $\mathrm{Ri}_{c}$ and interpolation of the $\mathrm{Ri}_{b}$ profile to $\mathrm{Ri}_{c}$ yielded the smallest errors in BLD. Using values of 0.25 and 0.30 for $\mathrm{Ri}_{c}$, Seidel et al. (2012) found that uncertainties in the BLD were $<50$ and $<80 \mathrm{~m}$ at the 50 th and 75 th percentiles, respectively, whereas interpolation errors yielded BLD uncertainties of $\sim 100$ and $\sim 150 \mathrm{~m}$ at the 50th and 75 th percentiles, respectively. The vertical resolution of the rawinsonde data, as well as errors caused by using $0 \mathrm{~m} \mathrm{~s}^{-1}$ for the surface wind speeds, were nontrivial error sources in the computed BLDs, particularly for shallow ABLs (i.e., ABLs $<1 \mathrm{~km}$ deep) in which BLD errors were as high as $50 \%$ (Seidel et al. 2012). Surface wind speed errors yield BLD errors of $\sim 50-200 \mathrm{~m}(\sim 200-600 \mathrm{~m})$ at the 50th (75th) percentiles (Seidel et al. 2012), which are comparable to the errors we identified in the present work.

\section{Summary and concluding remarks}

We used 35 years of rawinsonde observations from three sites in the contiguous United States to investigate the impact of errors of thermodynamic and kinematic variables on retrieved BLDs, allowing for a quantitative assessment of the $\delta$ BLD based on large datasets over land. The thermodynamic and kinematic errors arise due to 1) inherent errors in the rawinsonde measurements themselves based on manufacturerreported uncertainties, and 2) errors caused by the environment (e.g., radiative effects on the thermodynamic measurements). We found similarities among the three sites, which were located in different geographic and climactic

TABLE 5. Mean 2.5th and 97.5th percentiles of BLD differences over all stations for biases in the $u$ and $v$ wind components, ranging from -5.0 to $5.0 \mathrm{~m} \mathrm{~s}^{-1}$ in increments of $0.5 \mathrm{~m} \mathrm{~s}^{-1}$.

\begin{tabular}{|c|c|c|c|c|}
\hline $\operatorname{Bias}\left(\mathrm{m} \mathrm{s}^{-1}\right)$ & $\begin{array}{c}\overline{\delta \mathrm{BLD}}, 2.5 \text { th-percentile } \\
u \text { component }(\mathrm{m})\end{array}$ & $\begin{array}{c}\overline{\delta \mathrm{BLD}}, 97.5 \text { th-percentile } \\
u \text { component }(\mathrm{m})\end{array}$ & $\begin{array}{c}\overline{\delta \mathrm{BLD}}, 2.5 \text { th-percentile } \\
v \text { component }(\mathrm{m})\end{array}$ & $\begin{array}{c}\overline{\delta \mathrm{BLD}}, 97.5 \text { th-percentile } \\
v \text { component }(\mathrm{m})\end{array}$ \\
\hline-5.0 & -704.8 & 431.9 & -568.7 & 591.5 \\
\hline-4.5 & -653.8 & 397.3 & -538.2 & 539.2 \\
\hline-4.0 & -601.7 & 361.7 & -508.5 & 492.0 \\
\hline-3.5 & -549.2 & 321.0 & -470.6 & 443.8 \\
\hline-3.0 & -481.9 & 285.4 & -427.4 & 394.5 \\
\hline-2.5 & -414.3 & 241.3 & -368.1 & 343.6 \\
\hline-2.0 & -343.9 & 204.7 & -306.8 & 280.3 \\
\hline-1.5 & -259.2 & 153.6 & -240.4 & 208.6 \\
\hline-1.0 & -176.3 & 104.0 & -166.2 & 140.6 \\
\hline-0.5 & -86.3 & 53.5 & -83.9 & 71.3 \\
\hline 0.0 & 0.0 & 0.0 & 0.0 & 0.0 \\
\hline 0.5 & -49.4 & 86.3 & -69.1 & 87.7 \\
\hline 1.0 & -88.6 & 173.6 & -135.1 & 173.9 \\
\hline 1.5 & -121.8 & 264.9 & -196.6 & 252.6 \\
\hline 2.0 & -154.7 & 352.1 & -247.3 & 331.4 \\
\hline 2.5 & -176.6 & 430.6 & -293.8 & 391.5 \\
\hline 3.0 & -193.3 & 497.1 & -335.2 & 454.7 \\
\hline 3.5 & -211.2 & 555.4 & -371.1 & 500.8 \\
\hline 4.0 & -225.4 & 611.6 & -406.1 & 546.1 \\
\hline 4.5 & -235.1 & 667.7 & -429.4 & 591.5 \\
\hline 5.0 & -240.9 & 731.1 & -453.3 & 633.6 \\
\hline
\end{tabular}


regimes, when inducing perturbations to the rawinsondederived thermodynamic and kinematic fields. For example, for a $-2^{\circ} \mathrm{C}\left(+2^{\circ} \mathrm{C}\right)$ bias in temperature, $\overline{\delta B L D}$ ranged from -15 to $200 \mathrm{~m}$ (from -214 to $18 \mathrm{~m}$ ); for a $-5 \%$ ( $+5 \%$ ) RH bias, $\overline{\delta B L D}$ ranged from -302 to $7 \mathrm{~m}$ (from 2 to $249 \mathrm{~m}$ ). In the case of a $\pm 2 \mathrm{~m} \mathrm{~s}^{-1}$ bias in the zonal and meridional wind components, BLD errors were around $\pm 300 \mathrm{~m} . \overline{\delta \mathrm{BLD}}$ increased as a function of BLD when introducing errors to the thermodynamic fields, and $\overline{\delta \mathrm{BLD}}$ decreased as a function of BLD when introducing errors to the kinematic fields.

As the $\mathrm{Ri}_{b}$ approach is the most widely applicable method for computing BLDs from rawinsonde observations, the findings in this study expand upon previous work quantifying errors in BLDs from rawinsondes (e.g., Seidel et al. 2012; Dupont et al. 2020) by providing a framework to determine the sensitivity and the range of expected BLD errors due to errors in rawinsonde-derived temperature, $\mathrm{RH}$, and wind measurements. This work also proposes a new approach to identify the dependencies of these errors across a range of BLDs that frequently occur due to diverse meteorological conditions.

Furthermore, this work underscores that errors in BLD estimates obtained from rawinsondes are not systematic, which is important because rawinsondes are oftentimes used as the primary source for ABL and upper-air observations. These errors can be problematic when performing BLD climatologies across multiple seasons and for multiple geographic and climatic regions. For this reason, we recommend that, when BLDs from rawinsondes are reported, there also needs to be an uncertainty reported with these values. Utilizing these uncertainties is also important when comparing rawinsonde-derived BLDs with different datasets, including both profile-derived BLDs (i.e., BLDs obtained from lidars, sodars, AERIs, etc.) and BLDs obtained from numerical simulations. In lieu of the quantified errors in $\delta \mathrm{BLD}$, we recommend using quality flags, providing metadata based on the errors in the thermodynamic variables via routine sensor calibrations on seasonal scales, and/or reporting ascent rates of the rawinsondes over the lower part of the troposphere (e.g., 1.5 times the BLD).

In future work, similar sensitivity analyses as those presented in the present study should be applied to other approaches that can be used for determining BLDs from rawinsondes (e.g., the parcel method, height of the elevated inversion), as well as from other surface-based and remote sensing instruments (water vapor and temperature lidars, microwave radiometers) used to determine the BLD (e.g., Behrendt et al. 2005; Cimini et al. 2013; Dupont et al. 2020). Other future research avenues include the exploration of BLD errors for 1) different atmospheric stability regimes, 2) seasonal changes in surface forcing, 3) complex ABL regimes (e.g., coastal regions, complex terrain, interface of urban-rural regions), and 4) diverse advection regimes (e.g., Pal and Lee 2019a,b; Pal et al. 2020).

Acknowledgments. Coauthor S. Pal was supported by a Texas Tech University start-up research grant and was given a Texas Tech University Open Access Publication Initiative award to defray the cost for the open-access fee. In addition, we thank the three anonymous reviewers whose suggestions helped us to improve the paper. Last, we note that all results and conclusions of this study, as well as any views expressed herein, are those of the authors and do not necessarily reflect those of NOAA or the U.S. Department of Commerce.

Data availability statement. The rawinsonde datasets used in this study were obtained from ftp://ftp.ncdc.noaa.gov/pub/ data/igra/data/.

\section{REFERENCES}

Acevedo, O. C., and D. R. Fitzjarrald, 2001: The early evening surface-layer transition: Temporal and spatial variability. J. Atmos. Sci., 58, 2650-2667, https://doi.org/10.1175/15200469(2001)058<2650:TEESLT > 2.0.CO;2.

Behrendt, A., G. Wagner, A. Petrova, M. Shiler, S. Pal, T. Schaberl, and V. Wulfmeyer, 2005: Modular lidar systems for highresolution 4-dimensional measurements of water vapor, temperature, and aerosols. Proc. SPIE, 5653, 220-227, https:// doi.org/10.1117/12.579139.

Beyrich, F., 1997: Mixing height estimation from sodar data-A critical discussion. Atmos. Environ., 31, 3941-3953, https:// doi.org/10.1016/S1352-2310(97)00231-8.

Boutle, I. A., R. J. Beare, S. E. Belcher, A. R. Brown, and R. S. Plant, 2010: The moist boundary layer under a mid-latitude weather system. Bound.-Layer Meteor., 134, 367-386, https:// doi.org/10.1007/s10546-009-9452-9.

Cimini, D., F. De Angelis, J.-C. Dupont, S. Pal, and M. Haeffelin, 2013: Mixing layer height retrievals by multichannel microwave radiometer observations. Atmos. Meas. Tech., 6, 29412951, https://doi.org/10.5194/amt-6-2941-2013.

Clark, N. E., S. Pal, and T. R. Lee, 2020: Frontal modification of atmospheric boundary layer dynamics over land in midlatitudes. 20th Symp. on Meteorological Observations and Instrumentation, Boston, MA, Amer Meteor. Soc., 366768, https://ams.confex.com/ ams/2020Annual/webprogram/Paper366768.html.

Connell, B. H., and D. R. Miller, 1995: An interpretation of radiosonde errors in the atmospheric boundary layer. J. Appl. Meteor., 34, 1070-1081, https://doi.org/10.1175/1520-0450(1995) 034<1070:AIOREI >2.0.CO;2.

Conzemius, R. J., and E. Fedorovich, 2006: Dynamics of sheared convective boundary layer entrainment. Part I: Methodological background and large-eddy simulations. J. Atmos. Sci., 63, 1151-1178, https://doi.org/10.1175/JAS3691.1.

Dabberdt, W. F., and Coauthors, 2005: Multifunctional mesoscale observing networks. Bull. Amer. Meteor. Soc., 86, 961-982, https://doi.org/10.1175/BAMS-86-7-961.

Dupont, J.-C., M. Haeffelin, J. Badosa, G. Clain, C. Raux, and D. Vignelles, 2020: Characterization and corrections of relative humidity measurement from Meteomodem M10 radiosondes at midlatitude stations. J. Atmos. Oceanic Technol., 37, 857-871, https://doi.org/10.1175/JTECH-D-18-0205.1.

Durre, I., and X. Yin, 2008: Enhanced radiosonde data for studies of vertical structure. Bull. Amer. Meteor. Soc., 89, 1257-1262, https://doi.org/10.1175/2008BAMS2603.1.

Everett, L., 2018: The Future of Atmospheric Boundary Layer Observing, Understanding, and Modeling. National Academies Press, 58 pp., https://doi.org/10.17226/25138.

Fedorovich, E., and R. Conzemius, 2008: Effects of wind shear on the atmospheric convective boundary layer structure and evolution. Acta Geophys, 56, 114-141, https://doi.org/10.2478/ s11600-007-0040-4. 
Feltz, W. F., W. L. Smith, R. O. Knuteson, H. E. Revercomb, H. M. Woolf, and H. B. Howell, 1998: Meteorological applications of temperature and water vapor retrievals from the ground-based Atmospheric Emitted Radiance Interferometer (AERI). J. Appl. Meteor., 37, 857-875, https://doi.org/10.1175/15200450(1998)037<0857:MAOTAW>2.0.CO;2.

Garratt, J. R., 1994: Review: The atmospheric boundary layer. Earth-Sci. Rev., 37, 89-134, https://doi.org/10.1016/00128252(94)90026-4.

Hardesty, R., and R. Hoff, 2012: Thermodynamic profiling technologies workshop report to the National Science Foundation and the National Weather Service. NCAR Tech. Note NCAR/ TN-488+STR, 80 pp., https://doi.org/10.5065/D6SQ8XCF.

Hennemuth, B., and A. Lammert, 2006: Determination of the atmospheric boundary layer height from radiosonde and lidar backscatter. Bound.-Layer Meteor., 120, 181-200, https:// doi.org/10.1007/s10546-005-9035-3.

Holzworth, G. C., 1964: Estimates of mean maximum mixing depths in the contiguous United States. Mon. Wea. Rev., 92, 235-242, https://doi.org/10.1175/1520-0493(1964)092<0235: EOMMMD $>2.3 . \mathrm{CO} ; 2$.

_ 1967: Mixing depths, wind speeds and air pollution potential for selected locations in the United States. J. Appl. Meteor., 6, 1039-1044, https://doi.org/10.1175/1520-0450(1967)006<1039: MDWSAA $>2.0 . \mathrm{CO} ; 2$.

Kalthoff, N., H.-J. Binder, M. Kossmann, R. Vögtlin, U. Corsmeier, F. Fiedler, and H. Schlager, 1998: Temporal evolution and spatial variation of the boundary layer over complex terrain. Atmos. Environ., 32, 1179-1194, https://doi.org/10.1016/S1352-2310(97) 00193-3.

Kossmann, M., R. Vögtlin, U. Corsmeier, B. Vogel, F. Fiedler, H.-J. Binder, N. Kalthoff, and F. Beyrich, 1998: Aspects of the convective boundary layer structure over complex terrain. Atmos. Environ., 32, 1323-1348, https://doi.org/10.1016/ S1352-2310(97)00271-9.

Kretschmer, R., C. Gerbig, U. Karstens, and F.-T. Koch, 2012: Error characterization of $\mathrm{CO}_{2}$ vertical mixing in the atmospheric transport model WRF-VPRM. Atmos. Chem. Phys., 12, 2441-2458, https://doi.org/10.5194/acp-12-2441-2012.

Lee, T. R., and S. F. J. De Wekker, 2016: Estimating daytime planetary boundary layer heights over a valley from rawinsonde observations at a nearby airport: An application to the Page Valley in Virginia, United States. J. Appl. Meteor. Climatol., 55, 791-809, https://doi.org/10.1175/JAMC-D-150300.1.

_ regular rawinsonde measurements for elucidating key climatological and spatiotemporal patterns of afternoon boundary layer depths over the contiguous US. Adv. Meteor., 2017, 6841239, https://doi.org/10.1155/2017/6841239.

— S. F. J. De Wekker, and S. Pal, 2018: The impact of the afternoon planetary boundary-layer height on the diurnal cycle of $\mathrm{CO}$ and $\mathrm{CO}_{2}$ mixing ratios at a low-altitude mountaintop. Bound.-Layer Meteor., 168, 81-102, https://doi.org/10.1007/ s10546-018-0343-9.

Lenschow, D. H., B. B. Stankov, and L. Mahrt, 1979: The rapid morning boundary-layer transition. J. Atmos. Sci., 36, 2108-2124, https://doi.org/10.1175/1520-0469(1979)036<2108: TRMBLT $>2.0 . \mathrm{CO} ; 2$.

Liu, C., E. Fedorovich, and J. Huang, 2018: Revisiting entrainment relationships for shear-free and sheared convective boundary layers through large-eddy simulation. Quart. J. Roy. Meteor. Soc., 144, 2182-2195, https://doi.org/10.1002/qj.3330.
Liu, S., and X.-Z. Liang, 2010: Observed diurnal cycle climatology of planetary boundary layer height. J. Climate, 23, 5790-5809, https://doi.org/10.1175/2010JCLI3552.1.

MacCready, P. B., Jr., 1965: Comparison of some balloon techniques. J. Appl. Meteor., 4, 504-508, https://doi.org/10.1175/ 1520-0450(1965)004<0504:COSBT>2.0.CO;2.

Magnus, G., 1844: Versuche über die Spannkräfte des Wasserdampfs. Ann. Phys., 137, 225-247, https://doi.org/10.1002/andp. 18441370202.

Menut, L., C. Flamant, J. Pelon, and P. H. Flamant, 1999: Urban boundary-layer height determination from lidar measurements over the Paris area. Appl. Opt., 38, 945-954, https:// doi.org/10.1364/AO.38.000945.

Muppa, S. K., A. Behrendt, F. Späth, V. Wulfmeyer, S. Metzendorf, and A. Riede, 2016: Turbulent humidity fluctuations in the convective boundary layer: Case studies using water vapour differential absorption lidar measurements. Bound.-Layer Meteor., 158, 43-66, https://doi.org/10.1007/s10546-015-0078-9.

Nyeki, S., and Coauthors, 2000: Convective boundary layer evolution to $4 \mathrm{~km}$ ASL over high-alpine terrain: Airborne lidar observations in the Alps. Geophys. Res. Lett., 27, 689-692, https://doi.org/10.1029/1999GL010928.

Pal, S., 2019: ACT-America: Profile-based planetary boundary layer heights, eastern USA. ORNL DAAC, accessed 14 October 2020, https://doi.org/10.3334/ORNLDAAC/1706.

—_, and M. Haeffelin, 2015: Dynamics and forcing mechanisms governing diurnal and seasonal variability in the atmospheric boundary layer depths over a suburban site near Paris: A fiveyear long lidar-based study. J. Geophys. Res., 120, 1193611 956, https://doi.org/10.1002/2015JD023268.

__ and T. R. Lee, 2019a: Contrasting air mass advection explains significant differences in boundary layer depth seasonal cycles under onshore versus offshore flows. Geophys. Res. Lett., 46, 2846-2853, https://doi.org/10.1029/2018GL081699.

$\longrightarrow$, and $\longrightarrow, 2019 \mathrm{~b}$ : Advected airmass reservoirs in the downwind of mountains and their roles in overrunning boundary layer depths over the plains and valleys. Geophys. Res. Lett., 46, 10 140-10149, https://doi.org/10.1029/2019GL083988.

, and Coauthors, 2012: Spatio-temporal variability of the atmospheric boundary layer depth over the Paris agglomeration: An assessment of the impact of the urban heat island intensity. Atmos. Environ., 63, 261-275, https://doi.org/10.1016/ j.atmosenv.2012.09.046.

— S. F. J. De Wekker, and G. D. Emmitt, 2016: Investigation of the spatial variability of the convective boundary layer heights over an isolated mountain: Cases from the MATERHORN2012 experiment. J. Appl. Meteor. Climatol., 55, 1927-1952, https://doi.org/10.1175/JAMC-D-15-0277.1.

— T. R. Lee, and N. Clark, 2020: Mississippi and Missouri River flooding and its impact on atmospheric boundary layer dynamics. Geophys. Res. Lett., 47, e2019GL086933, https:// doi.org/10.1029/2019GL086933.

Pino, D., J.-P. Kaikkonen, and J. Vilà-Guerau de Arellano, 2013: Quantifying the uncertainties of advection and boundary layer dynamics on the diurnal carbon dioxide budget. J. Geophys. Res., 118, 9376-9392, https://doi.org/10.1002/jgrd.50677.

Piringer, M., 1988: The determination of mixing heights by sodar in an urban environment. Environmental Meteorology, Springer, 425-444.

San José, R., and J. Casanova, 1988: An empirical method to evaluate the height of the convective boundary layer by using small mast measurements. Atmos. Res., 22, 265-273, https:// doi.org/10.1016/0169-8095(88)90021-X. 
Seibert, P., F. Beyrich, S.-E. Gryning, S. Joffre, A. Rasmussen, and P. Tercier, 2000: Review and intercomparison of operational methods for the determination of the mixing height. Atmos. Environ., 34, 1001-1027, https://doi.org/10.1016/ S1352-2310(99)00349-0.

Seidel, D. J., C. A. Ao, and K. Li, 2010: Estimating climatological planetary boundary layer heights from radiosonde observations: Comparison of methods and uncertainty analysis. J. Geophys. Res., 115, D16113, https://doi.org/10.1029/ 2009JD013680.

_- Y. Yhang, A. Beljaars, J.-C. Golaz, A. R. Jacobson, and B. Medeiros, 2012: Climatology of the planetary boundary layer over the continental United States and Europe. J. Geophys. Res., 117, D17106, https://doi.org/10.1029/ 2012JD018143.

Sokolovskiy, S., Y.-H. Kuo, C. Rocken, W. S. Schreiner, D. Hunt, and R. A. Anthes, 2006: Monitoring the atmospheric boundary layer by GPS radio occultation signals recorded in the open-loop mode. Geophys. Res. Lett., 33, L12813, https:// doi.org/10.1029/2006GL025955.

Stull, R. B., 1988: An Introduction to Boundary Layer Meteorology. Kluwer Academic, 666 pp.

Tangborn, A., B. Demoz, B. J. Carroll, J. Santanello, and J. L. Anderson, 2020: Assimilation of lidar planetary boundary layer height observations. Atmos. Meas. Tech., submitted, https://doi.org/10.5194/AMT-2020-238, in press.

Vogelezang, D. H. P., and A. A. M. Holtslag, 1996: Evaluation and model impacts of alternative boundary-layer height formulations. Bound.-Layer Meteor., 81, 245-269, https://doi.org/ 10.1007/BF02430331.

von Engeln, A., and J. Teixeira, 2013: A planetary boundary layer height climatology derived from ECMWF reanalysis data. J. Climate, 26, 6575-6590, https://doi.org/10.1175/JCLI-D-12-00385.1.

Wang, J., J. Bian, W. O. Brown, H. Cole, V. Grubišić, and K. Young, 2009: Vertical air motion from T-REX radiosonde and dropsonde data. J. Atmos. Oceanic Technol., 26, 928-942, https://doi.org/10.1175/2008JTECHA1240.1.

Wang, X. Y., and K. C. Wang, 2014: Estimation of atmospheric mixing layer height from radiosonde data. Atmos. Meas. Tech., 7, 1701-1709, https://doi.org/10.5194/amt-7-1701-2014.

Winker, D. M., W. H. Hunt, and M. J. McGill, 2007: Initial performance assessment of CALIOP. Geophys. Res. Lett., 34, L19803, https://doi.org/10.1029/2007GL030135.

WMO, 2017: Observing Systems Capability Analysis and Review tool. WMO, www.wmo-sat.info/oscar/.

_ 2018: Statement of guidance for global numerical weather prediction (NWP). WMO Rep., 12 pp., www.wmo.int/pages/ prog/www/OSY/SOG/SoG-Global-NWP.pdf. 